\title{
Cationic Solid Lipid Nanoparticles of Resveratrol for Hepatocellular Carcinoma Treatment: Systematic Optimization, in vitro Characterization and Preclinical Investigation
}

This article was published in the following Dove Press journal:

International Journal of Nanomedicine

Mahfoozur Rahman,' Waleed H Almalki, ${ }^{2}$ Obaid Afzal, (D) ${ }^{3}$ Abdulmalik Saleh Alfawaz Altamimi, ${ }^{3}$ Imran Kazmi, ${ }^{4}$ Fahad A Al-Abbasi, ${ }^{4}$ Hani Choudhry, Sattam K Alenezi, ${ }^{6}$ Md Abul Barkat, (1) $)^{7}$ Sarwar Beg, (1D ${ }^{8}$ Vikas Kumar,' Abdulsalam Alhalmi ${ }^{9}$

'Department of Pharmaceutical Sciences, Shalom Institute of Health \& Allied Sciences, Sam Higginbottom University of Agriculture, Technology \& Sciences, Allahabad, India; ${ }^{2}$ Department of Pharmacology and Toxicology, College of Pharmacy, Umm AlQura University, Makkah, Saudi Arabia; ${ }^{3}$ Department of Pharmaceutical Chemistry, College of Pharmacy, Prince Sattam Bin Abdulaziz University, AlKharj II 942, Saudi Arabia; ${ }^{4}$ Department of Biochemistry, Faculty of Science, King Abdulaziz University, Jeddah, Saudi Arabia; ${ }^{5}$ Department of Biochemistry, Cancer Metabolism \& Epigenetic Unit, Faculty of Science, King Fahd Center for Medical Research, King Abdulaziz University, Jeddah, Saudi Arabia;

${ }^{6}$ Department of Pharmacology \& Toxicology, Unaizah College of Pharmacy, Qassim University, Qassim, Saudi Arabia;

${ }^{7}$ Department of Pharmaceutics, College of Pharmacy, University of Hafr Al Batin, Al Jamiah, Hafr Al Batin, Saudi Arabia; ${ }^{8}$ Department of Pharmaceutics, School of Pharmaceutical Education and Research, Nanomedicine Research Lab, Jamia Hamdard, New Delhi, India; ${ }^{9}$ Department of Pharmaceutical Science, Collage of Pharmacy, Aden University, Aden, Yemen

Correspondence: Abdulsalam Alhalmi Department of Pharmaceutical Science, Collage of Pharmacy, Aden University, Aden, Yemen Correspondence

Email aa.abdulla@pharm.adenuniv.com
Aim: The present study focuses on the development and evaluation of the resveratrol (RV)loaded cationic solid lipid nanoparticles (RV-c-SLNs) for the management of hepatocellular carcinoma (HCC).

Materials and Methods: Optimization of formulation was performed using factorial design, and further in vitro drug release, cytotoxicity, biodistribution, in vivo preclinical, and biochemical evaluation were carried out.

Results: The optimized formulation exhibited uniform size, homogeneous disparity, positive zeta potential, and stability over 12 -week storage at $25^{\circ} \mathrm{C} / 60 \% \mathrm{RH}$. The in vitro drug release and cytotoxicity study showed $60 \%$ drug release within the first 6 hours and comparatively higher cytotoxicity on HepG2 cell line by resveratrol-solid lipid nanoparticle (RV-SLN) as compared to the RV solution. In addition, an anticancer action and biodistribution study on a rat model of HCC showed significant reduction of tumor volume and higher accumulation in the tumor tissue from RV-c-SLN $(P<0.01)$ over RV solution and RV-SLN. Furthermore, RV-c-SLN showed significant downregulation in the levels of pro-inflammatory cytokines and balancing of antioxidant enzymes. Histopathological investigation showed reduced occurrence of hepatic nodules, necrosis formation, infiltration of inflammatory cells, blood vessels inflammation, and cell swelling.

Conclusion: Overall, the obtained results construed that RV-c-SLN with improved antitumor activity as clearly evident from in vitro, in vivo, and biochemical investigations.

Keywords: resveratrol, cationic solid lipid, solid lipid nanoparticles, inflammatory biomarkers, hepatocellular carcinoma, diethyl nitrosamine

\section{Introduction}

Liver cancer is a major concern worldwide. The world's fifth most dangerous neoplasm and third most common cause of cancer-related death is hepatocellular carcinoma (HCC). ${ }^{1}$ HCC is most prevalent amongst solid tumors, ${ }^{1,2}$ and develops due to induction of chronic inflammation in the liver, either due to persistence of hepatitis B, C, or any other liver infection. At the world level, every year 620,000 cases received. In $80 \%$ of these instances, Africa, South East Asia, and China were reported. HCC mainly accounts for $70-85 \%$ of crucial malignant tumors of the liver. $^{1,2}$ Further their expansion is caused by 
development of chronic inflammation by persistent viral infection (hepatitis B and C), metabolic (non-alcoholic fatty liver, hereditary hemochromatosis, and diabetes), food additive, immune related (autoimmune hepatitis and primary biliary cirrhosis), air water, pollutant, chemicals, and toxins. Recently, epidemiological studies revealed the increasing number of $\mathrm{HCC}$ patients in developed countries. ${ }^{2}$ HCC therapy is generally classified between curative and palliative therapies. Though surgical resection is the main curative procedure, it is mostly confined to patients with several or metastatic tumors. ${ }^{2}$ In the last few years, tremendous efforts have been made by researchers to identifythe cancer chemotherapeutic agents. Therefore, the synthetic anticancer drugs come up with therapeutic effects, but it has certain limitations due to carrying of severe toxicity, side-effects, and non-specific targeting potentials. Thus, successful chemotherapeutic agents are needed to improve the survival rate of HCC patients. Another option which is well documented is the use of herbals; they have a potential role to alter $\mathrm{HCC}^{2-4}$ Now researchers focus on phytoconstituents, which are emerging as multitherapeutic potential for management of cancer. They are versatile, safer on application, and cheaper. $^{1,2}$ There is numerous literature available on naturally occurring bioactives, which gained immense popularity for management of cancer. Among phytoconstituents, resveratrol found prominent antitumor effects on various cancer cells and have been extensively reviewed by researchers. ${ }^{3}$

Resveratrol (RV) is a (trans-3,5,40-trihydroxystilbene) phytoalexin found in many plant species such as grapes, peanuts, and berries. ${ }^{3}$ Literature reports indicate the use of resveratrol at the dose of $25-300 \mathrm{mg} / \mathrm{kg}$ body weight reduced the appearance and multiplicity of hepatocyte nodule in diethyl nitrosamine (DEN) treated animals over who did not receive RV. Moreover, the cellular architecture of the liver tissue was also improved by RV treatment. ${ }^{3}$ DEN is a widely using hepatotoxin for induction of HCC in animals for experimental studies. ${ }^{2,3}$ Despite the benefits of RV, it shows poor oral bioavailability and higher metabolism, which further limits its therapeutic potential in the treatment of cancer. To overcome these problems, the use of solid lipid nanoparticles (SLN) can be an effective alternative. ${ }^{4}$ SLN material has already been licensed for use in pharmaceutical or cosmetic products such as triacyl glycerides, diacylglycerides, monoacyl glycerides, waxy or fatty acids, and surfactants authorized in medical goods for use. ${ }^{4}$ It provides controlled drug release that is feasible for industrial scale production. ${ }^{4}$ Furthermore, many researchers have documented an enhanced intracellular supply of anticancer drugs as reported in our previous study to develop ganoderic acid-loaded SLNs and nanolipid carriers. ${ }^{4}$ Cationic SLN (c-SLN) is a cationic lipid/surfactant that is used in the production of low water-soluble therapeutic drugs. ${ }^{5}$ As compared to SLN, which has negative surface charge, the cationic SLN have greater affinity to cell membranes and serum proteins. ${ }^{5}$ In fact, it stimulates cellular receptor interaction and cellular uptake. $^{5,6}$

The work described focuses on systemic development of the resveratrol-loaded cationic SLNs (RV-c-SLNs) using a quality by design approach, followed by in vitro characterization and cytotoxicity studies on the HePG2 cell line. Further, in vivo pharmacokinetic and biodistribution studies were performed to evaluate the improvement in the biopharmaceutical and preclinical performance of the drug against HCC.

\section{Materials and Methods Chemicals}

Resveratrol and DEN were obtained from Sigma Aldrich (USA). Solid lipids, ie, Cap MCM C10, were obtained from M/s Gattefosse (Cedex, France). Cetyl trimethyl ammonium bromide (CTAB), Lutrol F68 (Poloxamer 188), and Tween- 80 were purchased from M/s Fisher Scientific (Chandigarh, India). Deionized triple-distilled water (M/s Millipore, Mumbai, India) was used for all the experiments throughout the study. All other ingredients, solvents, and reagents used in the analysis were of analytical reagent quality and used as obtained.

\section{Risk Assessment Studies}

Identification of high-risk critical material attributes (CMAs) was performed by a risk assessment study, where factors influential on the critical quality attributes (CQAs) were identified. ${ }^{7}$ For risk assessment, an Ishikawa fish-bone diagram was drawn using Minitab 17 software (M/S Minitab Inc., PA, USA) to determine the cause-and-effect relationship among the formulation attributes and process parameters on the CQAs of SLNs. Moreover, for identifying the medium-to-high risk factors with critical impact on the formulation CQAs, a risk estimation matrix (REM) was constructed for the purpose. The factors were discriminated by assigning low, 
medium, and high-risk rankings on the basis of prior knowledge and experience. ${ }^{7}$

\section{Selection of the Lipid}

The solubility of RV was determined in various lipids viz. Capmul MCMC10, stearic acid, cetyl alcohol, GMS, Compritol ATO888, and soy lecithin. Excess $\mathrm{RV}$ was applied to the vials comprising $500 \mathrm{mg}$ of solid lipid and held in a thermostatically controlled bath shaker for 24 hours at a set temperature of 80 $\pm 2^{\circ} \mathrm{C}$. ${ }^{8}$ The clear supernatant fraction from each of the samples was separated individually, and further dissolved in ethanol for quantification of the drug content using a developed and validated LCMS method of resveratrol. ${ }^{8}$

\section{Cationic-SLNs and SLN Production}

The RV-SLN was prepared using a hot-high-pressure homogenization system as stated by Rahman et $\mathrm{al}^{4}$ in a previous study with appropriate modifications., ${ }^{5}$ The variety of solid lipid used in SLN preparation was selected based on a solubility study. In this respect, a solution consisting of solid lipid (Capmul MCM C10; 270-525 mg) had to heat up to around $10^{\circ} \mathrm{C}$ higher than the solid lipid melting point. Simultaneously, the aqueous surfactant solution (Tween 80; $140-250 \mathrm{mg}$ ) was heated to $70^{\circ} \mathrm{C}$. In the aqueous phase, the lipid layer was spread with Ultra Turrax (IKA GmbH, Germany) at the same condition used for c-SLN development. Pre-emulsion was homogenized by a LAB 40 homogenizer (40 mL; APV, Germany) as similar to that used in c-SLN development. ${ }^{4,5}$

\section{Systematic Optimization of RV-c-SLN}

A systematic approach was used for optimizing the critical formulation factors with the help of experimental design for obtaining the desired responses. In this regard, three factors were selected such as concentration of Capmul MCMC10 (270-525 mg), concentration of CTAB (0.25-1.0\%), concentration of surfactant (ie, Tween 80 (T-80) 140-250 mg) for optimization of the c-SLNs, while factors such as concentration of RV and homogenization speed were fixed as constant. Response surface methodology was employed for estimating the factor-response relationship and identifying the optimized nanoparticle formulation. Box-Behnken Design (BBD) was applied on the selected factors with the help of Design Expert ${ }^{\circledR}$ software 8.0.7.1 (Stat-Ease Inc, Minneapolis, USA) at 3-levels, which produced a total of 15 experimental runs including five replicates of the center point formulations. The response surface plots (RSP) and counter plots (CP) were used for analyzing the interactions between the CMAs and CQAs. The mathematical modeling of experimental data was carried out and the optimized formulation was identified by numerical and graphical optimization techniques.

\section{Characterization of RV-c-SLN Particle Size (PS), Polydispersity Index (PDI), and

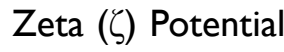

A particle size analyzer uses a dynamic light dispersal (DLS) technique to measure the average polydispersity index (PDI) and particle size after 200-fold aqueous solution accompanied by heavy shaking to get 100-250kilogram counts per second. The analyzer was then diluted. ${ }^{9}$ The zeta potential was measured using Zetasizer ZS 90 (M/s Malvern Instruments, Worcestershire, UK) by a dynamic light diffusion process.

\section{Photo Microscopy}

The optimized RV-c-SLN was labeled with an appropriate magnification using an optical microscope for the morphological surface study (Medilux, Kyowa opticals Co. Ltd, Hashimoto, Japan).

\section{Transmission Electron Microscope (TEM)}

The M-10 (Philips, The Netherlands) Transmission Electron Microscope (TEM) has been used to microscopically test equipped nano-formulations. One drop of RV-c-SLN was applied to a carbon-coated grid with a phosphotungstic acid solution, treated, and dried for 30 seconds. The dry exposed grid was moved to the slide and covered by a cover slip and put under the TEM at $60-80 \mathrm{KV}$.

\section{Loading Capacity (LC) and Encapsulation Efficiency (EE)}

The drug loading potential in nanoparticles tests content is performed after isolation from medium. ${ }^{10}$ The EE is associated with the percentage of product that is effectively trapped/adsorbed into c-SLN. The LC and EE of RVc-SLNs are established by dividing free resveratrol from the c-SLNs by calculating a difference between the initial quantity of resveratrol and the amount of supernatant after centrifugation at $11,000 \mathrm{rpm}$ and for a period of 30 minutes. ${ }^{10}$ In addition, the free RV contained in the supernatant was calculated by liquid chromatography of high 
performance. In addition, Equations 1 and 2 were used to calculate the LC and EE of drug, respectively. ${ }^{11}$

$$
L C=\frac{\text { Entrapped Drug }}{\text { SLN weight }} \times 100
$$

$$
E E(\%)=\frac{\begin{array}{l}
\text { Total amount } \\
\text { of RV }
\end{array} \quad \begin{array}{l}
\text { Amount of } \\
\text { Resveratrol in } \\
\text { total supernatent }
\end{array}}{\text { Amount of RV }} \times 100
$$

\section{In vitro Drug Release Study}

In vitro studies of RV-c-SLN were performed to evaluate the release pattern of the drug. It was done by dialysis method in which RV-c-SLNs were incubated at $37 \pm 1^{\circ} \mathrm{C}$ in $50 \mathrm{~mL}$ of saline phosphate buffer (pH 7.4). Aliquot samples were taken at various time intervals, and the amount of RV was calculated to determine the average percentage of drug release vs the period.

\section{In vitro Cytotoxic Activity}

The in vitro cytotoxic activity of RV was performed in Human hepatic carcinoma cell line (HePG2 cells weres purchased from NCCS Pune, India). Dulbecco's modified Eagle (DMEM) medium, 10\% (v/v) fetal bovine serum (FBS), $1 \mathrm{~mm}$ L-glutamine, $100 \mathrm{U} / \mathrm{mL}$ of penicillin, and $100 \mathrm{mg} / \mathrm{mL}$ of streptomycin were used to provide the requisite nutrients. Further, the cells were held at the $37^{\circ} \mathrm{C}$ and $5 \% \mathrm{CO}_{2} / 95 \%$ air conditions and the (3-[4,5-dimethylthiazol-2-yl]-2,5-diphenyltetrazolium bromide) assay was employed for evaluation of cytotoxicity of RV on the HepG2 cell line. ${ }^{12}$ In short, the cell line has been seeded in 96 well-plated seeds between 24 and 48 hours at $37^{\circ} \mathrm{C}$ with the moisturized RV incubator (10-60 $\mu \mathrm{g} / \mathrm{mL})$. The MTT $(10 \mu \mathrm{L})$ solution was then added into all plates after incubation in the saline phosphorous buffer and incubated for 2 hours at $37^{\circ} \mathrm{C}$. An ELISA platform reader (BioTek, USA) was used to calculate the optical density at $570 \mathrm{~nm}$ and cell viability.

$$
\% \text { cell inhibition }=100-\left\{\frac{\text { Test }}{\text { Control }}\right\} \text { X100 }
$$

Graph pad prism software is used to assess half the maximum level of inhibition $\left(\mathrm{IC}_{50}\right)$.

\section{Stability Studies}

Binder KBF-240 climate chambers (Binder Gmb Hfi Ltd., Munchen, Germany) evaluated the stability of the optimized SLN. ${ }^{13}$ Studies of stability were performed at $25^{\circ} \mathrm{C} / 60 \%$ RH and $40^{\circ} \mathrm{C} / 75 \% \mathrm{RH}$. The formulations have been packed into $100 \mathrm{~g}$ glass ointment jars and securely sealed. Stability was assessed at $0,1,2,4,8$ and 12 weeks after storage. The formulation was tested at each pull time and did not return to the chamber of stability. The formulations were tested for parameters known as criteria to evaluate the stability of the colloidal system, including particle size, PDI, EE, and LC.

\section{In vivo Preclinical Study Animal Study}

The preclinical study of Albino wistar male rats has been conducted (125-175 g body weight). The research rats were procured from the central animal house and housed in polypropylene cages in standard experimental conditions $\left(25 \pm 2^{\circ} \mathrm{C}\right.$ and $60-80 \% \mathrm{RH}, 12$ hours dark/light). The rats got a standard pellet and water diet ad libitum. Both research procedures have been tested and approved in accordance with the provisions of the Institutional Animal Ethical Committee (IAEC) and have been permitted by Dehradun (Ind), Siddhartha College of Pharmacy (Reg. No. SIP/IAEC/PCOL/06/2017), to track and control animal tests. Furthermore, both experimental experiments associated with animals were carried out in accordance with the relevant IAEC standards and regulations.

\section{Induction of HCC}

The rats received a single intraperitoneal DEN buffer injection $(200 \mathrm{mg} / \mathrm{kg})$ with the exception of normal control. The DEN and the normal control are treated with RVc-SLN and assessed in HCC after 10 days by the amount of alpha fetoprotein (AFP).

\section{Experimental Procedure}

The rats were split randomly into nine classes of nine individuals. Group I received a single daily dosage of $0.9 \% \mathrm{w} / \mathrm{v}$ normal saline $5 \mathrm{~mL} / \mathrm{kg} /$ day p.o. (orally), and were considered the control group. Group II were administered with resveratrol (RV) at a dose of $100 \mathrm{mg} / \mathrm{kg}$ in $5 \mathrm{~mL} / \mathrm{kg} /$ day p.o. for 14 weeks, Group III were DEN control administered with DEN at a dose of $200 \mathrm{mg} / \mathrm{kg}$, Group IV DEN control rats received RV at a dose of $12.5 \mathrm{mg} / \mathrm{kg}$ in a single dose of $5 \mathrm{~mL} / \mathrm{kg} /$ day p.o. for 14 weeks. Group V were DEN control rats administered with $\mathrm{RV}$ at a dose of $25 \mathrm{mg} / \mathrm{kg}$ in a $5 \mathrm{~mL} / \mathrm{kg}$ /day p.o. for 14 weeks, Group VI DEN control rats received RV at a dose of $50 \mathrm{mg} / \mathrm{kg}$ in a single dose of $5 \mathrm{~mL} / \mathrm{kg} /$ day p.o. 
for 14 weeks, Group VII, DEN control rats administered with RV at a dose of $100 \mathrm{mg} / \mathrm{kg}$ containing a single dose of $5 \mathrm{~mL} / \mathrm{kg}$ /day p.o. for 14 weeks, Group VIII, DEN control rats administered with RV-SLN containing $50 \mathrm{mg} / \mathrm{kg}$ in a single dose containing $5 \mathrm{~mL} / \mathrm{kg} /$ day p.o. for 14 weeks, Group IX, DEN control rats received RV-cationic-SLN $(50 \mathrm{mg} / \mathrm{kg}$ ) containing a single dose of $5 \mathrm{~mL} / \mathrm{kg} /$ day p.o. for 14 weeks. Blood samples and hepatic tissues were gathered to validate the hepatic tumor for macroscopic inspection at the conclusion of the experimental study and to measure relative tumor volume (RTV), ${ }^{5,12}$ and further tissues/organs were used to predict biodistribution, biochemical, and histopathological examination. ${ }^{12}$ The tumor could expand for a full volume $\left(\mathrm{mm}^{3}\right)$ for 150 days. The treated groups are RV solution, RV-SLN, and RV-c-SLN, which were allocated to these after the macroscopical results. Animal weight and tumor volume were assessed every 10 days after treatment and were sacrificed for harvesting the tumor. Furthermore, the tumor volume was determined by calculating three orthogonal tumor diameters as one-half of the diameter of product.

\section{Biodistribution Studies}

The rat-bearing hepatic tumor was randomly distributed to three classes $(n=9)$ and injected intravenously through the tail with the same dosage in the three separate categories, $\mathrm{RV}$ solution $(50 \mathrm{mg} / \mathrm{kg})$, RV-SLN (50 mg/kg), and RVc-SLN $(50 \mathrm{mg} / \mathrm{kg})$. After administering formulations, each group rat was sacrificed at 8 hours. The essential organs, such as heart, kidneys, lung, spleen, and liver and tumor, were collected. Furthermore, all tissue of the above organs and tumor were homogenized and RV was extracted with methanol and water $(60: 40 \mathrm{v} / \mathrm{v})$. The quantity of RV in each organ/tumor tissue was calculated by LCMS (Mass Lynx V4.1 SCN918). Further, isocratic mobile phase consists of methanol and water (60: 40 $\mathrm{v} / \mathrm{v}$ ), which pumped at a constant flow rate of $0.1 \mathrm{~mL} /$ min at the injected dose of $10 \mu \mathrm{L}$, and the retention timewas found (Rt 1.48). Furthermore, the data were determined in terms of tissue weight $(\mu \mathrm{g} / \mathrm{g}$ tissue).

\section{Preparation of Hepatic Tissue}

The hepatic tissue of all group rats has been excised, cleansed with saline ice, and homogenized in a Tris- $\mathrm{HCl}$ tank used the TH homogenizer, centrifuged for 30 minutes at $4{ }^{\circ} \mathrm{C}$ at $10,000 \mathrm{rpm}$, and collected for the biochemical estimate of enzyme markers.

\section{Hepatic Tissue Markers}

A number of hepatic enzyme markers have been determined from the liver tissue of different animal groups, which includes alanine transaminase (ALT), alkaline phosphatase (ALP), and aspartate transaminase (AST).

\section{Biochemical Parameters}

The biochemical parameters including albumin, total protein, and total bilirubin were calculated by adopting the method of Rahman et al. ${ }^{12}$ Membrane enzymes such as $\mathrm{Mg}^{2+}$ ATPase, $\mathrm{Ca}^{2+}$ ATPase, and $\mathrm{Na}^{+} / \mathrm{K}^{+}$-ATPase, which have been calculated with minor modifications, used the system stated by Rahman et al. ${ }^{12}$

\section{Antioxidant Parameters}

Phase I enzymes, such as NADH cytochrome b5, cytochrome reductase $\mathrm{P} 450$ and cytochrome reductase P420, were measured using the method reported by Rahman et $\mathrm{al}^{12}$ with a slight modification. The testing parameters in antioxidants which include malondialdehydes (MDA), glutathione (GSH), catalases (CAT), glycine peroxidases (GPx), superoxide dismutase (SOD), and myeloperoxidases (MPO) are evaluated with slight modification in the method reported by Rahman et al. ${ }^{12}$

\section{Inflammatory Mediators}

The use of commercially available diagnostic kits was reported to be pro-inflammatory cytokines like interleukin-1 $\beta$ (IL-1ß), interleukin-6 (IL-6), tumor necrosis factor$\alpha(\mathrm{TNF}-\alpha)$, and inflammatory mediator including NF- $\mathrm{kB}$.

\section{Statistical Data Analysis}

The individual variables were designed using the software Design Expert. Prism was used for mathematical analysis assessment. Through the Dunnett study, the whole findings were viewed as a mean \pm SEM and variance analysis (ANOVA). The $P$-values of $0.05,0.01$, and 0.001 were considered as significant.

\section{Results}

\section{Formulation and Optimization of RV-c-SLNs}

The c-SLNs have been made with the use of lipids from the preliminary solubility test of the product in strong shear homogenization processes. In addition, the solid lipid melting at the required levels of $397.5 \mathrm{mg}, 0.25 \%$ $\mathrm{w} / \mathrm{w}$ aqueous CTAB, and $195 \mathrm{mg}$ surfactant solution (T-80), pre-heated separately $\left(10^{\circ} \mathrm{C}\right.$ above the lipid melting point), was mixed with ultra-turrax (Ika, Staufen, 
Germany), for 10 minutes at 8,000 rpm and cooled down to ice and obtained c-SLN. Various formulation parameters were determined according to the systematic approach to formulation production utilizing the experimental design. These include particle size, zeta potential, EE, LC, and T90\% drugs. Supplementary Table-S1 displays the values for these physiochemical parameters for the formulations prepared in conjunction with the BBD.

\section{Response Surface Analysis and Selection of the Optimized Formulation}

The surface response study was conducted by using the experimental data collected for each parameter of the formulation CQAs. In order to generate a suitable mathematical model, the experimental data was fitted with the quadratic polynomial equation for each response variable. The Equations listed below (4-7) describe the interactions between the factors analyzed in response variables mathematically. Statistical assessment of model validity shows a $P$-value of $<0.05$, with a high value of the correlation coefficients of about 1 , while the model lack of fit was found to be quite negligible.

$$
\begin{aligned}
\text { Particle size }= & 195.00+73.38 * A+62.12 * B \\
& -46.50 * C+50.25 * A B-16.50 \\
& * A C-73.50 * B C+76.88 * A^{2} \\
& +121.88 * B^{2}+26.62 * C^{2} \\
P D I= & 0.21+0.098 * A+0.059 * B-0.031 * C \\
& +0.036 * A B-9.500 E-003 * A C-0.081 \\
& * B C+0.099 * A^{2}+0.11 * B^{2}+0.021 * C^{2}
\end{aligned}
$$

$$
\begin{aligned}
\text { Entrapment efficiency }= & 79.20-5.93 * A-2.18 * B \\
& +2.10 * C-1.81 * A B+1.28 \\
& * A C+6.11 * B C-10.17 \\
& * A^{2}-10.27 * B^{2}-8.66 * C^{2}
\end{aligned}
$$

$$
\begin{aligned}
\text { Drug release }= & 92.80-1.97 * A-1.47 * B+1.78 \\
& * C-2.81 * A B+2.92 * A C+3.04 \\
& * B C-6.96 * A^{2}-6.40 * B^{2}-2.22 \\
& * C^{2}
\end{aligned}
$$

Supplementary Table-S2-S5 enlist various ANOVA parameters according to the quadratic regression model. For all the standard safety assessment parameters, the table shows appropriate standards. The solution surface analysis has been performed using 2D and 3D plots on the basis of the chosen quadratic model, which unambiguously indicate the presence of an association between the factors being tested. Supplementary Fig-S1 (A-F) and Supplementary Fig-S2 (A-F) show 3D response surface plots and 2D contour plots for particle size and zeta potential, respectively, which suggest very similar effects of different formulation parameters on the formulation factors. A curvilinear influence was observed on particle size and zeta potential with an increase in the concentration of Capmul MCMC10 and CTAB. Smaller particle size and optimum zeta potential were observed at intermediate levels of Capmul MCM, CTAB, and T80, while an increase in these parameters yielded a drastic change in the size of particles. Supplementary Fig-S3 (A-F), Supplementary Fig-S4 (A-F), and Supplementary Fig-S5 (A-F) demonstrate the effect of various formulation influences on the LC, EE, and in vitro release $\left(\mathrm{T}_{90 \%}\right)$ of the drugs. Similarly, the 2D contours and 3D response surface plots display a curvilinear trend among the factors that generate "tomb-shaped" plots with maximum effects on the loading capacity, entrapment efficiency, and release of drugs at intermediary levels of all variable CMAs. The optimized formulation was identified through a computational analysis used a numerical desirability function with a value close to 1 , where all the CQAs were observed within the desired limits. Moreover, the optimized formulation was also demarcated in the overlay plot shown in Figure 1.

\section{Characterization of the Optimized RV-c-SLNs}

\section{Particle Size, PDI, Zeta Potential, and Optical Microscopy}

Figure 2A-E depicts the particle size distribution profile of the optimized RV-c-SLNs formulation with a size of $139 \mathrm{~nm}$ and PDI of 0.271. This indicated the nanostructured nature of the RV-loaded-c-SLN formulation of monodisperse nature. Zeta $(\zeta)$ potential values of RV-c-SLN were found to be $+50.25 \mathrm{mV}$, showing a positive charge of the said formulation. In general, the said formulation exhibits a positive zeta potential, ${ }^{5}$ which is near to that observed in the design approach of said formulation. The reason could be the free ammonium group of the CTAB polymer on the surface. The morphology of optimized formulation showed uniform morphology and a poor degree of aggregation by optical photomicrograph (as shown in Figure 2D). 


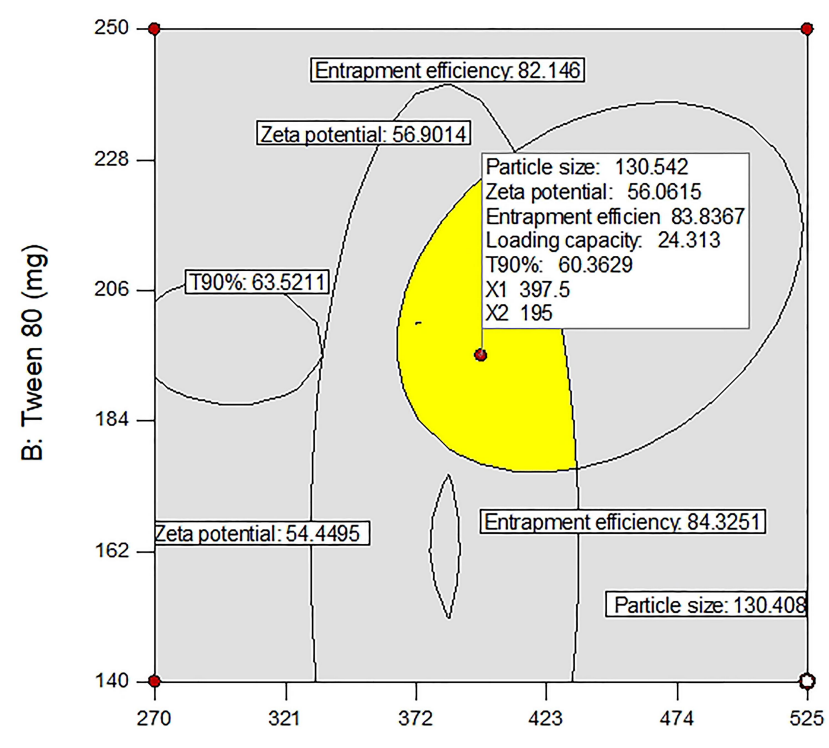

A: Capmul MCM (mg)

Figure I Overlay plot obtained from graphical optimization, indicating yellow region as design space and flagged point as the optimized resveratrol-loaded cationic solid lipid nanoparticles (RV-c-SLN).

\section{TEM Imaging}

TEM illustrated in Figure 2E indicates the spherical shape of said RV-c-SLN, which confirmed their nanometric size.

\section{Drug Loading Capacity (LC) and Entrapment Efficiency (EE)}

The optimized RV-c-SLNs exhibited an LC of 24.3\% and EE of $83.8 \%$, which indicated the optimum concentration of lipids, quantity of drug concentrations, and was employed for said nanoparticles. Besides, this also indicated the effectiveness of the method preparation and process parameters used for preparation of the nanoparticles.

\section{In vitro Drug Release}

Figure 3A shows the RV-c-SLN formulations in vitro releases produced in conformity with their experimental design. The various drug release characteristics were observed with maximum release of drugs, ie, $>60 \%$ within the first 6 hour period. The framework of higher and lower lipid concentrations suggests slower drug release rates. The results show that the release of c-SLN is a biphasic with initial releases of 0-6 hours, and the results indicated $\mathrm{RV}$ is present in the outer lipid layer of the SLN. The high level of RV in the exterior lipid shown by applying the $\mathrm{T}-80$ in the aqueous phase contributes to a surfactant lipid boundary layer enriched RV. However, the initial drug release may eventually decrease its surfactant layer on the surface, resulting in a sustained release of c-SLN due to the decomposition of the integrated lipid center. Mathematical modeling in vitro release data showed that the release of RV-c-SLNs is correlated with the first release kinetics with an $\mathrm{R}^{2}$ value of 0.9756 , which means that RV release from c-SLN is proportional to that in the $\mathrm{SLN}$ and the RV release decreases over time.

\section{In vitro Cytotoxicity Study}

Figure $3 \mathrm{~B}-\mathrm{C}$ shows the in vitro cytotoxic impact of $\mathrm{RV}$ on liver cancer cell line such as $\mathrm{HepG}_{2}$ cell lines for up to 24 to 48 hours. The different concentration of RV showed the cytotoxic effect. In addition, the least viable cells with RVc-SLN reported in 48 hours at lower $\mathrm{IC}_{50}$ (as shown in Supplementary Table-S6). The results suggest the necrobiosis effect of RV on the hepatic cells in a dose-dependent manner.

\section{Stability Studies}

\section{Particle Size, Size Distribution, and Zeta Potential}

The particle size of the optimized RV-c-SLN stored at $25^{\circ} \mathrm{C} /$ $60 \% \mathrm{RH}$ and $40^{\circ} \mathrm{C} / 75 \% \mathrm{RH}$ results in between $139.3 \mathrm{~nm}$ to $141.60 \mathrm{~nm}$ and $139.3 \mathrm{~nm}$ to $155.21 \mathrm{~nm}$, respectively (shown in Supplementary Tables S7 and S8). Overall, with c-SLN, the particle size improved during storage apart from the RVc-SLN kept at $25^{\circ} \mathrm{C} / 60 \% \mathrm{RH}$, which retained a fairly constant size or saw no variations. Particle growth was very slower in the case of storage at $25^{\circ} \mathrm{C} / 60 \% \mathrm{RH}$. While at $40 \% / 75 \% \mathrm{RH}$, the system's kinetic energy increases, leading to increased collisions among particles, resulting in aggregation and increased particle size. ${ }^{13}$ However, the PDI data reveal low and constant values ranging from $0.271-0.38$, and that values shown are physically stable in terms of particle size and PDI at the storage condition of $25^{\circ} \mathrm{C} / 60 \% \mathrm{RH}$ for at least 12 weeks (as shown in Supplementary Table-S7). The zeta potential data reveal non-significant variations over 12 weeks of storage at $25^{\circ} \mathrm{C} / 60 \% \mathrm{RH}$. Whereas storage conditions at $40^{\circ} \mathrm{C} / 75 \% \mathrm{RH}$, significant variations were found in zeta potential over 12 weeks, this may attribute due to increased particle size and enhancement of net positive charge on the surface of RV-c-SLNs, which further results in heterogenous dispersion.

\section{Encapsulation Efficiency (EE) and Loading Capacity (LC)} The EE of the optimized RV-c-SLN at $25^{\circ} \mathrm{C} / 60 \% \mathrm{RH}$ ranged from $83.8-79.21 \%$, whereas the loading capacity ranged from $24.2-23 \%$. The $\mathrm{EE}$ and $\mathrm{LC}$ of the said formulation at $40^{\circ} \mathrm{C} / 75 \% \mathrm{RH}$ ranged from $83.8-73.11 \%$ and LC, which ranged from $24.2-17.05 \%$, these are shown in 


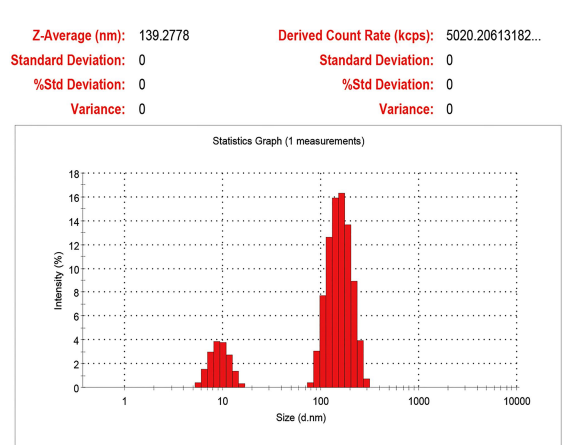

A

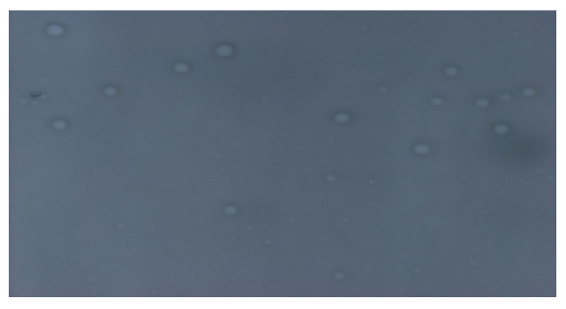

D

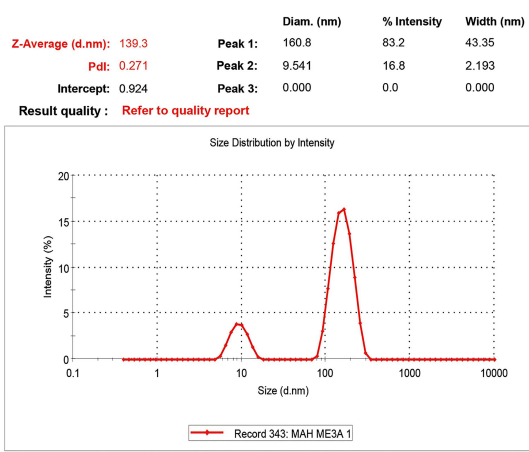

B

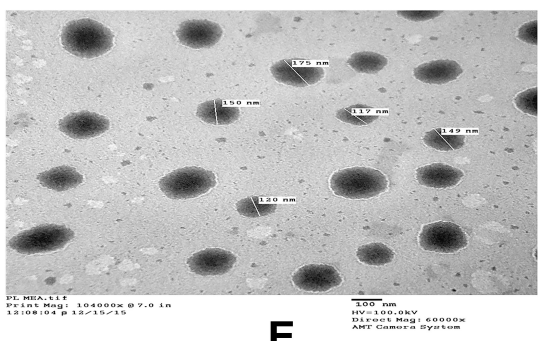

$\mathbf{E}$

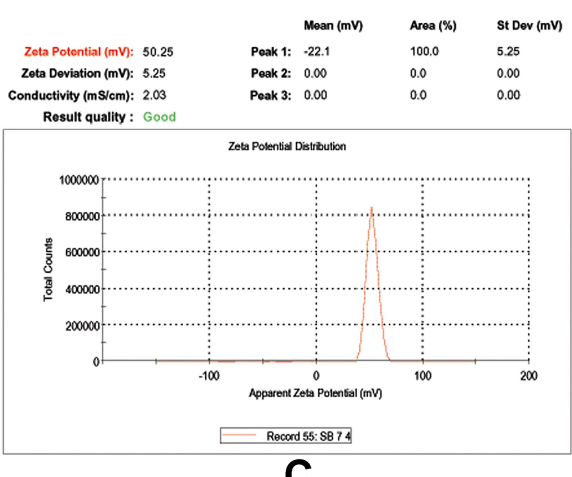

C

Figure 2 (A and B) Particle size distribution of optimized RV-c-SLN. (C) Zeta potential of optimized RV-c-SLN. (D) Revealed photo-microscopy of said formulation. (E) Transmission electron microscopy (TEM) of said formulation.

Abbreviation: RV-c-SLN, resveratrol-loaded cationic solid lipid nanoparticles.

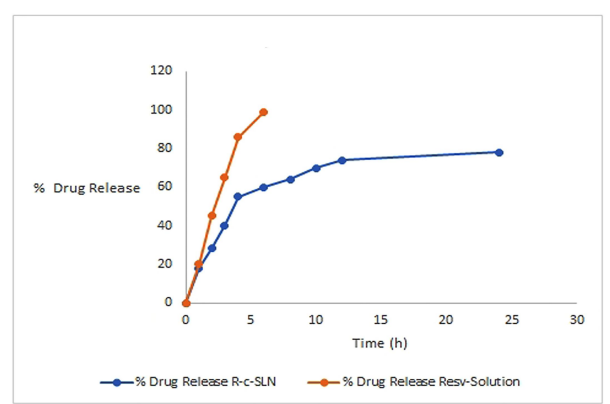

A

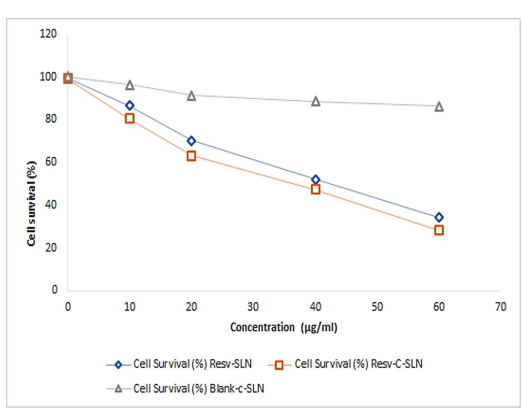

B

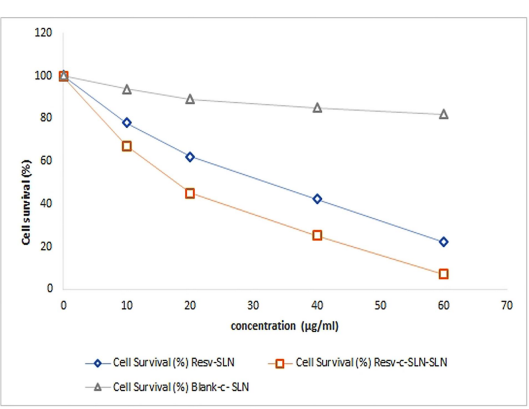

C

Figure 3 (A) In vitro release of RV-c-SLN and RV solution up to duration of 24 hours using the dialysis method in phosphate buffer saline (pH 7.4). (B) Assessment of cell viability of RV-SLN, RV-c-SLN, and Blank-c-SLN formulation at different concentrations following incubation with HepG2 cells for 24 hours and (C) the same for 48 hours. Abbreviations: RV, resveratrol; RV-c-SLN, resveratrol-loaded cationic solid lipid nanoparticle.

Supplementary Tables S7 and S8. Furthermore, the concentration of RV encapsulated in c-SLN remained constant or non-significant differences in 12 weeks of storage at $25^{\circ} \mathrm{C}$ / $60 \% \mathrm{RH}$. The EE and LC of the formulations, however, showed a significant decrease at storage temperatures of 40-75\% RH which may correspond with polymorphic forms of the lipid and the drug leakage. ${ }^{13}$

\section{In vivo Preclinical Studies}

The in vivo preclinical study was performed by the optimized RV-c-SLN formulation to estimating their anticancer potential on DEN induced HCC in rats. The animals in the normal group and RV treated group had normal hepatic tissue. Rats in the DEN group showed nodular expansion (white in color) and hepatic tissue decolorization indicating the progression of liver cancer (shown in Figure 4A). However, DEN rats treated with RV-SLN demonstrated improvement in the liver physiology by suppression of hepatic nodules and decolorization, which indicated its chemo-protective effect (as shown in Figure 4B). Furthermore, following treatment with RV-c-SLN, rats displayed no development of hepatic tissue nodules, except for slight decolorization of the surface of the hepatic tissue (as shown in Figure 4C). Tables 1 and 2 exhibit 


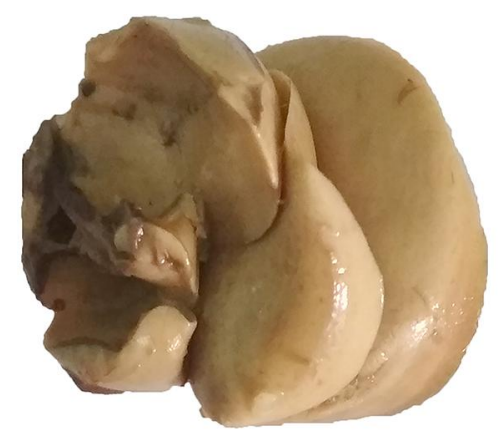

A

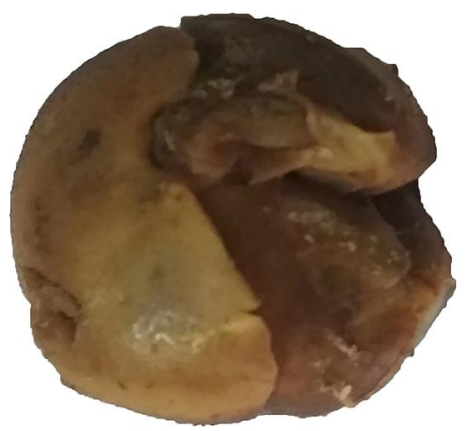

B

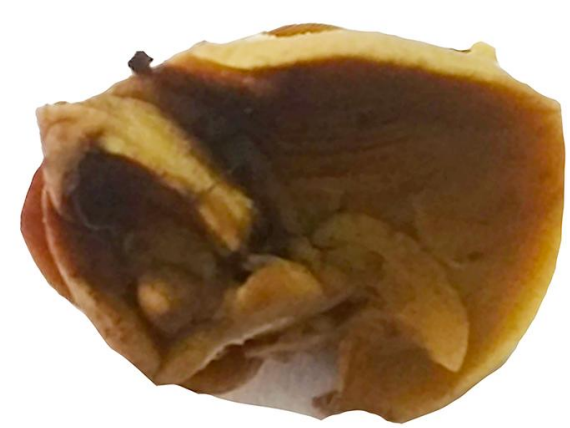

C

Figure 4 Macroscopic observations of HCC group rats induced by DEN. (A) The DEN control group demonstrated extension (in color) of the hepatic nodules and tissue decolourization, (B) The DEN-RV solution control group $(50 \mathrm{mg} / \mathrm{kg}$ ) revealed that the proliferation of pre-cancerous (white in color) nodules and shading of tissues were less than the DEN group, and (C) DEN control group treated with RV-cationic-SLN (50 mg/kg) reported the tissue color decolorization which was much less in contrast with $B$ group rats.

the data containing number of rats having an average number of nodules formed or not have nodules upon oral administration of treatment formulations. These tables suggest that, in the DEN group, all rats have expansion of hepatic nodules with $100 \%$ reported cases of HCC. RV solution $(50 \mathrm{mg} / \mathrm{kg}$ ) and RV-SLN (50 mg/kg) group rats showed lesser hepatic nodules, with tumor incidence varying between $55.5 \%$ and $33 \%$, while the RV-c-SLN (50 mg/ $\mathrm{kg}$ ) group showed a very smaller number of nodules limited to $11.1 \%$ tumor incidence.

Moreover, Table 1 data also represents the number of nodules and size of hepatic nodules in the animals treated with different treatment formulations. All the group rats were macroscopically scrutinized for estimating the size of hepatic nodules. The hepatic nodule size was divided into $\leq 1 \mathrm{~mm},<3 \mathrm{~mm}$ to $>1 \mathrm{~mm}$, and $\geq 3 \mathrm{~mm}$. DEN control rats demonstrated total 206 hepatic nodules, which further bifurcate into different sizes such as $107(\leq 1 \mathrm{~mm}), 52$ $(<3 \mathrm{~mm}>1 \mathrm{~mm})$, and $47(\geq 3 \mathrm{~mm})$ with $52 \%, 25 \%$, and $23 \%$ incidence of nodules. At the dose of the $50 \mathrm{mg} / \mathrm{kg}$ of $\mathrm{RV}$ administered in DEN rats effectively showed a total number of 85 nodules and revealed 40 ( $\leq 1 \mathrm{~mm}), 25$ $(<3 \mathrm{~mm}>1 \mathrm{~mm})$, and $20(\geq 3 \mathrm{~mm})$ with $47 \%, 29 \%$, and $23 \%$ of nodules incidence. DEN rats treated with RV $(100 \mathrm{mg} / \mathrm{kg})$ reduced to 37 nodules and revealed 18 ( $\leq 1 \mathrm{~mm}), 12(<3 \mathrm{~mm}>1 \mathrm{~mm})$ and $07(\geq 3 \mathrm{~mm})$ with $48 \%, 32 \%$, and $19 \%$ of nodule incidence. Whereas DEN rats treated with RV-SLN $(50 \mathrm{mg} / \mathrm{kg}$ ) found a total of 16 nodules and revealed $8(\leq 1 \mathrm{~mm}), 5(<3 \mathrm{~mm}>1 \mathrm{~mm}), 03$ ( $\geq 3 \mathrm{~mm}$ ) with $50 \%, 31 \%$, and $19 \%$ of nodules incidence

Table I Showed the Effect of Resveratrol in Different Dose, Optimized Dose, and Its Formulation on the Number of Rats, Number of Nodules, and Average Number of Nodules Bearing Rats

\begin{tabular}{|c|c|c|c|c|c|c|}
\hline \multirow[t]{2}{*}{ S. No } & \multirow[t]{2}{*}{ Groups } & \multirow{2}{*}{$\begin{array}{l}\text { Number of } \\
\text { Rats with } \\
\text { Nodules/ } \\
\text { Number of } \\
\text { Rats }\end{array}$} & \multirow{2}{*}{$\begin{array}{l}\text { Total } \\
\text { Number } \\
\text { of } \\
\text { Nodules }\end{array}$} & \multicolumn{3}{|c|}{$\begin{array}{l}\text { Relative Size (\% of Number } \\
\text { Size) }\end{array}$} \\
\hline & & & & $\leq \mathbf{l} \mathbf{~ m m}$ & $\begin{array}{l}<3 \mathrm{~mm} \\
>1 \mathrm{~mm}\end{array}$ & $\geq 3 \mathrm{~mm}$ \\
\hline $\mathbf{I}$ & Normal control group & $0 / 9$ & 00 & 00 & 00 & 00 \\
\hline 2 & Normal control treated with Resveratrol (RV) $(50 \mathrm{mg} / \mathrm{kg})$ & $0 / 9$ & 00 & 00 & 00 & 00 \\
\hline 3 & DEN control received single dose of DEN $(200 \mathrm{mg} / \mathrm{kg})$ & $9 / 9$ & 206 & $107(52)$ & $52(25)$ & $47(23)$ \\
\hline 4 & DEN control treated with RV $(12.5 \mathrm{mg} / \mathrm{kg})$ & $8 / 9$ & 148 & $74(50)$ & $42(28)$ & $32(21)$ \\
\hline 5 & DEN control treated with RV $(25 \mathrm{mg} / \mathrm{kg})$ & $7 / 9$ & 135 & $68(50)$ & $37(27)$ & $30(22)$ \\
\hline 6 & DEN control treated with RV $(50 \mathrm{mg} / \mathrm{kg})$ & $5 / 9$ & 85 & $40(47)$ & $25(29)$ & $20(23)$ \\
\hline 7. & DEN control treated with RV $(100 \mathrm{mg} / \mathrm{kg})$ & $3 / 9$ & 37 & $18(48)$ & $12(32)$ & $7(19)$ \\
\hline 8. & DEN control treated with RV-SLN $(50 \mathrm{mg} / \mathrm{kg})$ & $3 / 9$ & 16 & $8(50)$ & $5(31)$ & $3(19)$ \\
\hline 9. & DEN control treated with RV-c-SLN (50 mg/kg) & $1 / 9$ & 01 & $I(100)$ & 00 & 00 \\
\hline
\end{tabular}

Note: Group I and group II did not show the any sign of Hepatic nodules.

Abbreviations: DEN, diethyl nitrosamine; c-SLN, cationic solid lipid nanoparticles. 
Table 2 Showed the Effect of Resveratrol in Different Dose, Further Optimized Dose, and Its Formulation, on Number of Rats with Tumor Incidence

\begin{tabular}{|l|l|l|l|}
\hline S. No & Groups & $\begin{array}{l}\text { Number of Rats with Tumor/Number of } \\
\text { Rats }\end{array}$ & $\begin{array}{l}\text { Tumor Incidence } \\
\text { (\%) }\end{array}$ \\
\hline I & Normal control group & $0 / 9$ & 00 \\
$\mathbf{2}$ & Normal control treated with Resveratrol $(\mathrm{RV})(50 \mathrm{mg} / \mathrm{kg})$ & $0 / 9$ & 00 \\
$\mathbf{3}$ & DEN control received single dose of DEN $(200 \mathrm{mg} / \mathrm{kg})$ & $9 / 9$ & 100 \\
$\mathbf{4}$ & DEN control treated with RV (I $2.5 \mathrm{mg} / \mathrm{kg})$ & $8 / 9$ & 89 \\
$\mathbf{5 .}$ & DEN control treated with RV $(25 \mathrm{mg} / \mathrm{kg})$ & $7 / 9$ & 77.8 \\
$\mathbf{6 .}$ & DEN control treated with RV $(50 \mathrm{mg} / \mathrm{kg})$ & $5 / 9$ & 55.5 \\
$\mathbf{7 .}$ & DEN control treated with RV $(100 \mathrm{mg} / \mathrm{kg})$ & $3 / 9$ & 33.3 \\
$\mathbf{8 .}$ & DEN control treated with RV-SLN $(50 \mathrm{mg} / \mathrm{kg})$ & $3 / 9$ & 33.3 \\
$\mathbf{9 .}$ & DEN control treated with RV-c-SLN $(50 \mathrm{mg} / \mathrm{kg})$ & $1 / 9$ & 11.1 \\
\hline
\end{tabular}

Note: Group I and group II did not show any sign of hepatic nodules.

Abbreviations: DEN, diethyl nitrosamine; c-SLN, cationic solid lipid nanoparticles.

and DEN treated with RV-c-SLN (50 mg/kg) illustrated total number of nodules is $1(\leq 1 \mathrm{~mm})$ with $100 \%$ of nodules incidence (as shown in Table 1). Therefore, the results indicated better anticancer effects were found with at the dose of $50 \mathrm{mg} / \mathrm{kg}$ of RV-c-SLN in DEN treated rats, with a significant improvement in reducing the incidence of $\mathrm{HCC}$

\section{Effect of RV and Its Different Dose and Optimized Formulation on Body Weight and Liver Weight}

Figure $5 \mathrm{~A}$ demonstrates the body weight of various rats grouping after different treatment formulations have been administered. The rats given with the DEN control group demonstrated an increase in the body weight, not significant in comparison to the normal and treated group with administration of RV. A similar response was observed in a concentration dependent manner in rats treated with RVSLN and RV-c-SLN, where improvement of body weight was significant in comparison to the DEN control group. The normal control group and RV treated normal control group showed an almost similar liver weight. There was increased liver weight in the DEN control group rats, whereas in the RV treated DEN groups the liver weight was lowered (0.95- and 0.85-times lower at doses of 12.5 and $25 \mathrm{mg} / \mathrm{kg}$ ), but intthe RV treated group at the dose of $50 \mathrm{mg} / \mathrm{kg}$ had a 0.75 -times lower liver weight as compared to the DEN group. In the same way, DEN-RV at the dose of $100 \mathrm{mg} / \mathrm{kg}$ had a 0.7 -times lower liver weight over the DEN group. In a similar way, the DEN treated RV-SLN found a 0.6-times lower liver weight over the DEN group of rats. RV-c-SLN showed 0.5- and 0.6-times lower liver weight as compared to the normal control group and DEN group. Further, the RV-c-SLN formulation was found to be significant $(P<0.001)$ in comparison to the DEN control group rats. Figure 5B shows the liver weight of a different group of rats. Finally, it concludes that the optimized formulation (RV-c-SLN) found the highest improvement in body weight, and effectively decreased the liver weight as compared to the DEN group and other treated groups.

\section{Relative Tumor Volume and Biodistribution Studies}

The anticancer action was further tested at a dose of $50 \mathrm{mg} / \mathrm{kg}$ administered by oral route. RV solution, RVSLN, and RV-c-SLN (50 mg/kg) were given on day one week after tumor development. Figure 6 reveals that RVSLN and RV-c-SLN could inhibit tumor growth. Whereas in particular RV-c-SLN showed higher tumor regression with a significant difference compared with RV solution $(P<0.01)$ and RV-SLN $(P<0.05)$ on day 114. Moreover, with RV-c-SLN, the relative tumor volume at the end of study was $0.3 \pm 0.1$, as compared to RV-SLN $(2 \pm 1.01)$ and RV solution (2.4 \pm 1.07$)$.

The biodistribution of RV-c-SLN in the Albino wistar male rats bearing $\mathrm{HCC}$ was measured at 8 hours after oral administration. Figure 7 , in the case of RV-c-SLN, indicates that its concentration in the tumor was 2.6- and 1.4-times higher over RV solution and RV-SLN, respectively at 8 hours after oral administration. In addition, RVc-SLN was found to be lower distributed to the heart, kidney, lung, and higher distributed to the liver over RV solution and RV-SLN, respectively. Therefore, these results indicated that RV-c-SLN could result in significantly higher accumulation of $\mathrm{RV}$ in the liver and tumor by oral administration of RV-c-SLN over the other two mentioned formulations (shown in Figure 7). 


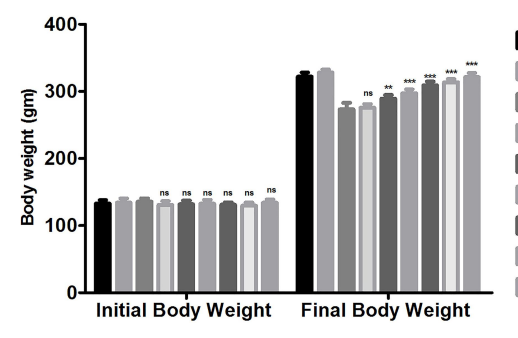

A

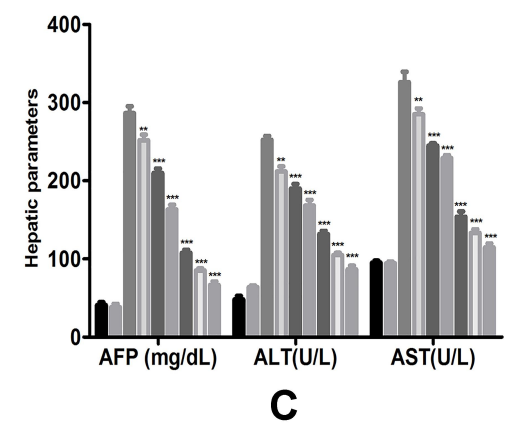

nC NC+RV $\square$ DEN $\square$ DEN+RV $(12.5 \mathrm{mg} / \mathrm{kg})$ DEN+RV $(25 \mathrm{mg} / \mathrm{kg})$ DEN+RV $(50 \mathrm{mg} / \mathrm{kg})$ DEN+RV $(100 \mathrm{mg} / \mathrm{kg})$ $\square$ DEN+RV-SLN DEN+RV-cationic SLN

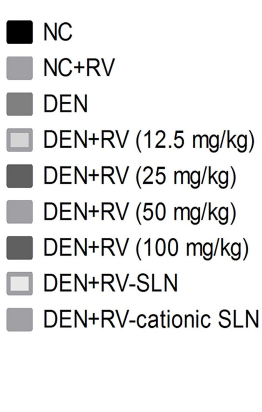

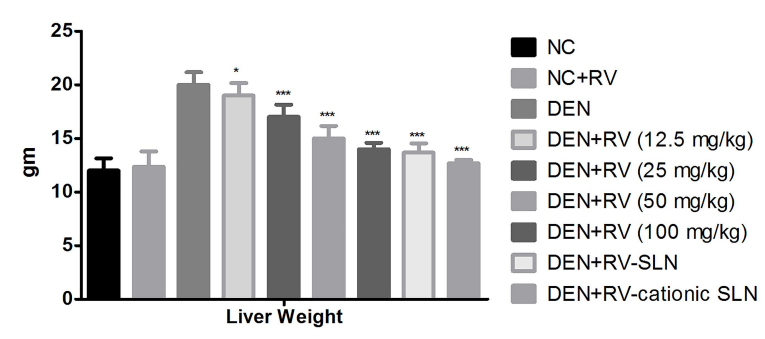

B

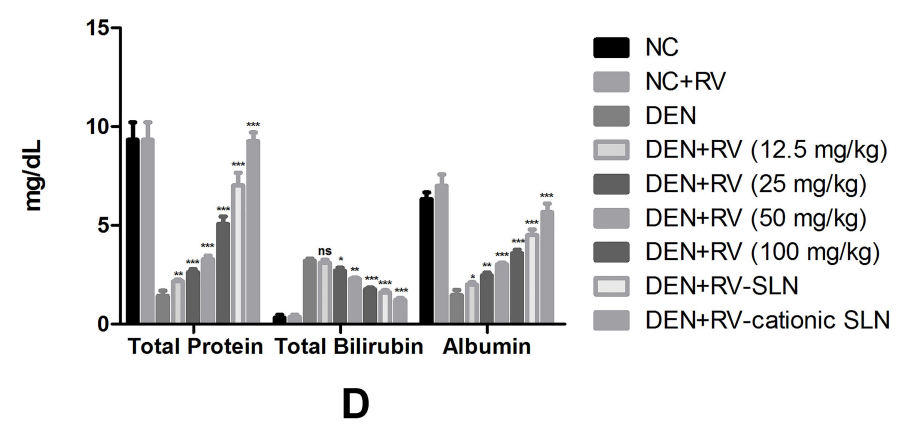

Figure 5 Effect of RV in the various doses $(12.5-100 \mathrm{mg} / \mathrm{kg}$ ) and RV-loaded formulation (both SLN and c-SLN at the dose of $50 \mathrm{mg} / \mathrm{kg}$ ) on the body weight of different groups of rats. (A) Initial and final body weight of rats, All the data correspond to mean \pm SEM ( $P>0.05$ (ns), $* * P<0.0$ I, $* * * P<0.00$ I, ( $* *$ significant, $* * *$ significant) 2 -way ANOVA followed by Dunnett's multiple comparison test and (B) liver weight (DEN, Diethyl nitrosamine; RV, Resveratrol). All the data correspond to mean $\pm S E M * P<0.05$, ***P<0.00I, (*significant, ***significant) 2-way ANOVA, followed by Dunnett's multiple comparison test). (C) Effect of resveratrol in the various dose (I2.5-I00 mg/kg) and resveratrol-loaded formulation (both SLN and c-SLN at the dose of $50 \mathrm{mg} / \mathrm{kg}$ ) on the hepatic parameter of different group of rats. All the data correspond to mean \pm SEM $(* * P<0.01$, $* * * P<0.001$ (** and $* * *$ significant) 2-way ANOVA, followed by Dunnett's multiple comparison test. (D) Effect of resveratrol in the various dose and resveratrolloaded formulation (SLN and c-SLN) on non-hepatic parameters of different groups of rats. All the data correspond to mean $\pm S E M(P>0.05$ (ns)) $(* P<0.05$, $* * P<0.01$, $* * * P<0.001),(*, * *$, and *** significant), 2-way ANOVA followed by Dunnett's multiple comparison test.

Abbreviations: AFP, alpha feto-protein; AST, aspartate aminotransferase; ALT, alanine aminotransferase; RV, resveratrol; ns, nonsignificant.

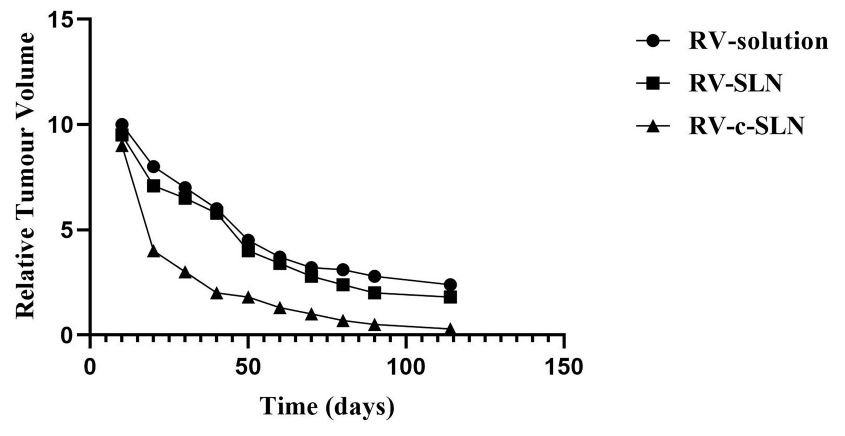

Figure 6 Relative tumor growth of RV solution, RV-SLN, and RV-c-SLN on rat bearing $\mathrm{HCC}$ after single dose $(50 \mathrm{mg} / \mathrm{kg})$ of oral administration. Statistical significance compared with RV solution and RV-SLN: $P<0.001$ and $P<0.01$.

\section{Effect of RV in Different Dose and RV-c-SLN on Hepatic and Non-Hepatic Parameters}

There was a significant variation in hepatic parameters of all group of rats. In fact, the serum concentration of alphafetoprotein (AFP) was observed higher in DEN group rats that remained high until the end of the experiment study. The $\mathrm{RV}$ treatment showed the down-regulation of AFP content in concentration-dependent manner. A similar pattern was observed in the RV-c-SLN treated group rats. Besides, an

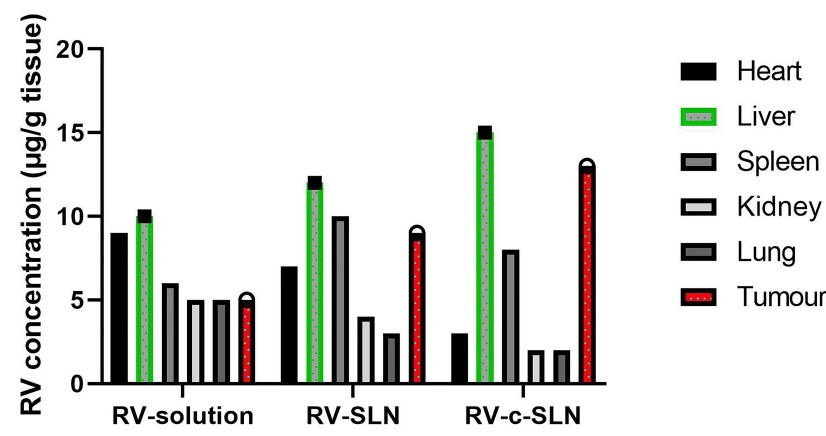

Figure 7 Biodistribution of RV in rat bearing $\mathrm{HCC}$ at 8 hours after administration of RV solution, RV-SLN, and RV-c-SLN, at the dose of $50 \mathrm{mg} / \mathrm{kg}$. Statistical significance compared with RV solution and RV-SLN: $P<0.01$ and $P<0.01$.

Abbreviation: RV, resveratrol.

analogous trend was also noted in other hepatic parameters such as AST, ALP, and ALT. There was a momentous boost up observed for these proteins during the disease and it was significantly $(P<0.001)$ down-regulated by the RV in a dosedependent manner. Most significant reductions of hepatic parameters in the aforementioned parameters were observed in the RV-c-SLN treated group as compared to DEN and other treatment group rats (Figure 5C). The normal control 
group and the RV treatment group were almost equal in all non-hepatic parameters with respect to total protein, albumin, and bilirubin. DEN-induced group rats had shown total protein down-regulation (1.43 \pm 0.05$)$, albumin (1.46 \pm 0.02$)$, and up-regulation of total bilirubin (3.2 \pm 0.32 ). RV solution showed an increase in the overall protein, albumin, and reduced total bilirubin, at the dose range of $12.5-100 \mathrm{mg} /$ $\mathrm{kg}$. Whereas RV-c-SLN showed the most significant increase in total protein, albumin, and the most significant reduction of the total bilirubin over the DEN group of rats (Figure 5D).

\section{Effect of RV in Different Doses and R-c-SLN on Antioxidant Enzymes}

The level of MDA (379.6 \pm 0.04$)$ was increased in the DEN control group over the normal control group and significantly $(P<0.001)$ restored after administration of RV at different doses $(12.5,25,50$, and $100 \mathrm{mg} / \mathrm{kg})$. But RV-SLN reduced the level of MDA (171.6 \pm 0.06$)$. Further, RV-c-SLN showed the most significant reduction in the MDA value (111.3 \pm 0.07$)$ and nearly reached the normal control group. Other parameters, including GPx (60.3 \pm 0.02$)$, GSH (30.3 \pm 0.04 ), SOD (9.3 \pm 0.06$)$, GST ( $8 \pm 0.03$ ), and CAT ( 31.3 $\pm 0.04)$ were decreased in the DEN control group as compared to the normal control group and significantly $(P<0.001)$ restored in the value of all those parameters after administration of RV solution at various mentioned doses. Whereas in the case of RV-SLN, GPx (46.3 \pm 0.04$)$, GSH (93.3 \pm 0.07$)$, SOD (27.3 \pm 0.04$)$, GST (27.6 \pm 0.07$)$, and CAT $(72 \pm 0.05)$ increased their values and reached near to the normal of the control group. Further, in the case of the RVc-SLN treated group revealed GPx (55 \pm 0.02$)$, GSH (105.3 $\pm 0.06)$, SOD (31.3 \pm 0.02$)$, GST (32.3 \pm 0.08$)$, and CAT ( 83.3 $\pm 0.04)$. Moreover, this particular group most effectively improved the values of said parameters and reached close to normal control group as compared to other treatment groups. Furthermore, all these are shown in Figure 8A-F.

\section{Effect of RV in Different Dose and RV-c-SLN on Membrane-Bound Enzymes}

The decrease of $\mathrm{Ca}^{2+}$ ATPase level was observed in the group induced by DEN as compared to the normal control group. RV solution, RV-SLN, and RV-c-SLN improved the $\mathrm{Ca}^{2+}$ ATPase level reached near to the normal control group in DEN treated rats (Figure 9A). Almost the similar pattern was also observed in the levels $\mathrm{Na}^{+} / \mathrm{K}^{+}$and $\mathrm{Mg}^{2}$ ${ }^{+}$ATPase in the DEN control group. The RV treated group which restored the $\mathrm{Na}^{+} / \mathrm{K}^{+}$and $\mathrm{Mg}^{2+}$ ATPase near to normal control level. Furthermore, RV-c-SLN in the DEN treated group, most effectively improved the $\mathrm{Na}^{+} / \mathrm{K}^{+}$and $\mathrm{Mg}^{2+}$ ATPase to normal control level as compared to other $\mathrm{RV}$ treated groups and the RV-SLN treated group.

\section{Effect on Inflammatory Mediators}

The level of pro-inflammatory cytokines viz., TNF- $\alpha$, IL-1 $\beta$, IL-6, and NF- K $\beta$ were found to up-regulate these inflammatory mediators in DEN group of rats. However, administration of RV treated DEN groups revealed controlled down-regulation of all these, which were shown in Figure 9B. RV-c-SLN most effectively revealed controlled

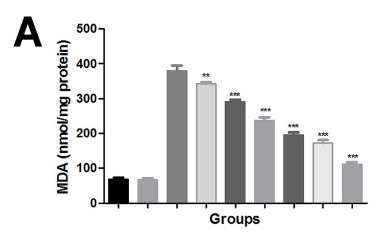

D

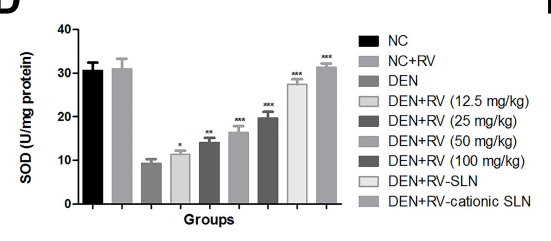

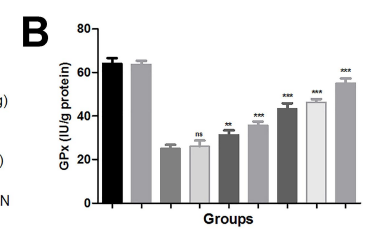

E

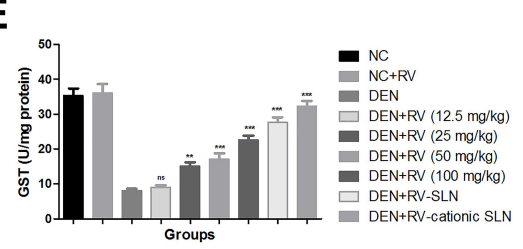

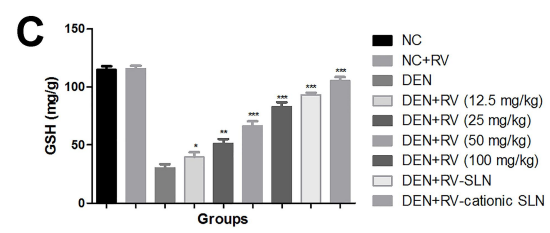

$\mathbf{F}$

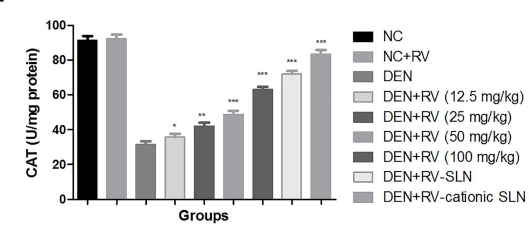

Figure 8 Effect of RV in the various dose $(12.5-100 \mathrm{mg} / \mathrm{kg}$ ) and RV-loaded formulation (both SLN and c-SLN at the dose of $50 \mathrm{mg} / \mathrm{kg}$ ) on antioxidant parameters of different group of rats. (A) MDA parameters. All the data correspond to mean \pm SEM ( $* * P<0.01$, $* * * P<0.00 \mathrm{I}$ ( $* *$ and $* * *$ significant) 2 -way ANOVA, followed by Dunnett's multiple comparison test). (B) GPx parameter, All the data correspond to mean \pm SEM (P>0.05 (ns), **P<0.0I, ***P<0.00I, (** and *** significant) 2 -way ANOVA, followed by Dunnett's multiple comparison test). (C) GSH parameter, All the data correspond to mean \pm SEM ( $* P<0.05$, $* * P<0.01$, ***P<0.00I) (*, $* *$, and $* * *$ significant), 2-way ANOVA, followed by Dunnett's multiple comparison test). (D) SOD parameter, All the data correspond to mean $\pm S E M(* P<0.05$, $* * P<0.01, * * * P<0.00 \mathrm{I}(*, * *$, and $* * *$ significant), 2-way ANOVA, followed by Dunnett's multiple comparison test). (E) GST parameter, All the data correspond to mean \pm SEM (P>0.05 (ns), $* * P<0.01$, $* * * P<0.00 \mathrm{I}$ (ns; nonsignificant, ** significant *** significant) 2-way ANOVA, followed by Dunnett's multiple comparison test). (F) CAT parameter, All the data correspond to mean \pm SEM $\left(* P<0.05, * * P<0.01, * * * P<0.001{ }^{*}, * *\right.$, and $* * *$ significant), 2-way ANOVA, followed by Dunnett's multiple comparison test.

Abbreviations: DEN, diethyl nitrosamine; RV, resveratrol; ns, nonsignificant. 

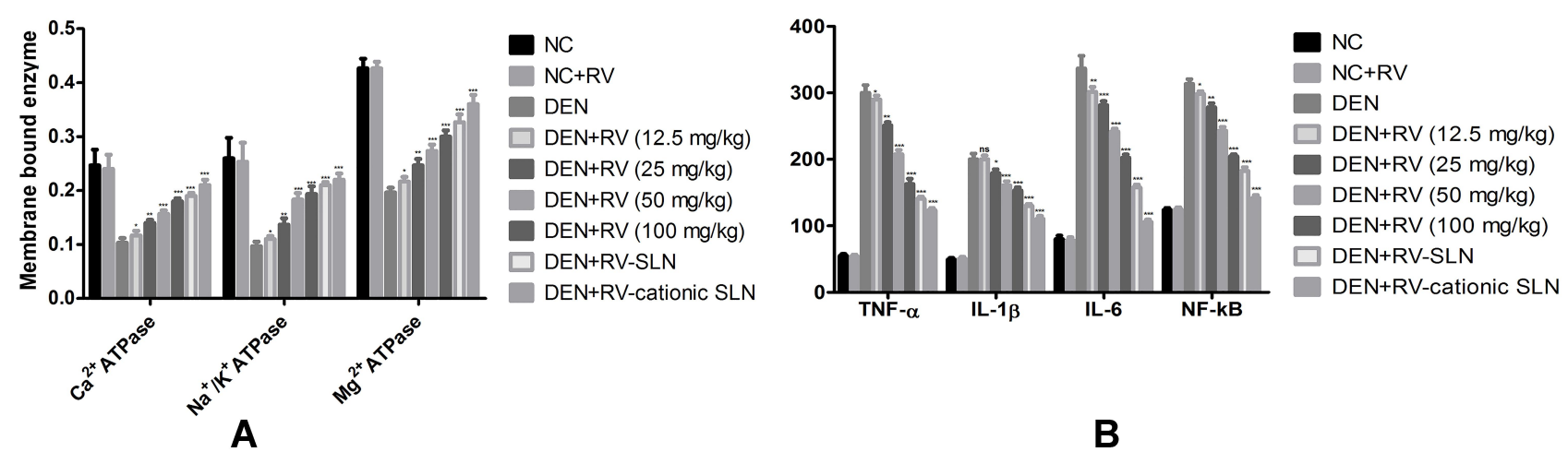

Figure 9 (A) Effect of RV in the various dose $(12.5-100 \mathrm{mg} / \mathrm{kg}$ ) and RV-loaded formulation (both SLN and c-SLN at the dose of $50 \mathrm{mg} / \mathrm{kg}$ ) on the membrane bound activity of different groups of rats. All the data correspond to mean \pm SEM $(P<0.05(*), P<0.01$ (**), $P<0.00 \mathrm{I}$ (***), 2-way ANOVA (*, **, and *** significant); ANOVA, followed by Dunnett's multiple comparison test. (B) Effect of RV in the various dose and RV-loaded formulation (SLN and c-SLN at the dose of $50 \mathrm{mg} / \mathrm{kg}$ ) on various mentioned inflammatory mediators of different groups of rats. All the data correspond to mean \pm SEM ( $P>0.05(\mathrm{~ns}), P<0.05(*), P<0.0 \mathrm{I}(* *), P<0.00 \mathrm{I}(* * *)(*, * *$, and $* * *$ significant), 2 -way ANOVA, followed by Dunnett's multiple comparison test.

Abbreviations: DEN, diethyl nitrosamine; RV, resveratrol; TNF- $\alpha$, tumor necrosis factor- $\alpha$; IL-I $\beta$, interlukin-I $\beta$; IL-6, interlukin-6; NF- $\mathrm{B}$, nuclear factor-kappa B; DEN, diethyl nitrosamine; RV, resveratrol; ns, non-significant.

down-regulation of aforementioned cytokines, as illustrated in Figure 9B.

\section{Effect on Histopathology}

The histopathology of liver tissue assessment of every group (figure not shown here). Animals in the normal control and RV-loaded normal control group showed no histopathological characteristics changes. HCC cells found inflamed blood vessels, cell necrosis, swelling of cells, thick cords of unsystemic hepatic parenchyma, irregular cells, rich sinusoids, irregular cytoplasm, pseudo acini, and basophilic. Eosinophil microdroplet of cytoplasm found in the hepatic tissue histopathology interface. DEN has verified its carcinogenic impact by nucleus enlargement and hyperplasia in the bile duct and by eruption of hepatic star cells in the portal area (shown in Table 3). RV treatment with histopathological rates, lower necrosis cells, inflammatory cells, HSC proliferation cells and decreased karyomegaly were observed relative to DEN group rats. RV-SLN reported few improvements in histopathology in

Table 3 Showed the Effect of Different Groups of Resveratrol on the Histopathology Character in HCC

\begin{tabular}{|c|c|c|c|c|c|c|c|}
\hline \multirow[t]{2}{*}{ S. No. } & \multirow[t]{2}{*}{ Histopathology Changes } & \multicolumn{6}{|c|}{ Groups } \\
\hline & & NC & $\begin{array}{l}\text { NC+RV } \\
(100 \mathrm{mg} / \mathrm{kg})\end{array}$ & DEN & $\begin{array}{l}\text { DEN+RV } \\
(50 \mathrm{mg} / \mathrm{kg})\end{array}$ & $\begin{array}{l}\text { DEN+RV-SLN } \\
(50 \mathrm{mg} / \mathrm{kg})\end{array}$ & $\begin{array}{l}\text { DEN+RV- } \\
\text { c-SLN }\end{array}$ \\
\hline I. & Necrosis & No & No & Yes & Yes & Yes & No \\
\hline 2. & Hydropic degeneration & No & No & Yes & No & No & No \\
\hline 3. & HSCs focal proliferation & No & No & Yes & No & No & No \\
\hline 4. & Bile cysts & No & No & Yes & Yes & Yes & Yes \\
\hline 5. & Pseudo-nucleoli & No & No & Yes & No & No & No \\
\hline 6. & Peliosis hepatis & No & No & Yes & Yes & No & No \\
\hline 7. & Disorganized hepatic parenchyma & No & No & Yes & Yes & No & No \\
\hline 8. & Apoptosis & No & No & Yes & Yes & Yes & No \\
\hline 9. & Hepatocelluar adenoma & No & No & Yes & Yes & Yes & Yes \\
\hline 10. & Cell necrosis & No & No & Yes & Yes & Yes & No \\
\hline II. & Altered basophilic & No & No & Yes & Yes & No & No \\
\hline 12. & Small dark cytoplasm & No & No & Yes & No & No & No \\
\hline 13. & Enlargement of karyomegali & No & No & Yes & Yes & Yes & No \\
\hline 14. & Macro lipid droplets & No & No & Yes & Yes & No & No \\
\hline 15. & Diffuse dysplasia & No & No & Yes & Yes & Yes & No \\
\hline 16. & Hyperplastic foci & No & No & Yes & Yes & No & No \\
\hline
\end{tabular}

Abbreviations: NC, normal control; RV, resveratrol; DEN, diethyl-nitrosamine; c-SLN, cationic-solid lipid nanoparticles; HSC, hepatic stellate cell. 
terms of lower necrosis, inflammatory cells, and karyomegaly enlargement. Whereas RV-c-SLN showed significant improvements in histopathology in terms of very fewer necrosis and inflammatory cells in histopathology.

\section{Discussion}

In the present study, we developed RV-c-SLNs and explored its efficacy by oral administration against DEN induced HCC rats. RV-c-SLNs significantly improved in the availability of RV to the tumor site and demonstrated the potential effect in DEN-induced $\mathrm{HCC}$ via multiple mechanisms. In $\mathrm{HCC}, \mathrm{RV}$ acted as a cancer protective agent but it has several limitations, which may overcome the dose and effective delivery to the site by using novel formulation, ie, cationic SLN. The unique properties of cationic-SLN including small size, sustained release characteristics, biocompatibility, and biodegradable nature make it an attractive drug delivery option in the management of HCC. The main factors, like particle size, particle size distribution, and zeta potential, have played an important role in drug release, cytotoxicity against $\mathrm{HepG}_{2}$ cell line, and drug stability. Therefore, in the present study, the optimized cationic-SLN have to provide novel characteristics with their optimized particle size and zeta potential, causing higher cytotoxicity of RV. Zeta potential can affect nanoparticle phagocytosis or pharmacokinetic characteristics of the body's nanosystems. ${ }^{5}$ While cancer cell surface, the anionic lipid components (eg, phosphatidylserine, anionic phospholipids, glycoproteins and proteoglycans) in the internal cell membrane make cell surface negative. ${ }^{5}$ This study found that higher cytotoxicity was observed with RV-c-SLN over RV-SLN in the $\mathrm{HepG}_{2}$ cell line. HCC involved multi-steps, with various stages of change in the biological system. Negative charges of the tumor vasculature's endothelial cell membranes might have potentiated the electrostatic activity between positively charged nanoparticles and the tumor. ${ }^{5}$ Over the traditional SLN who contained negative surface charge, the cationic charged SLN (as like other types of colloidal carrier in general) reported greater affinity towards the serum proteins, antioxidant enzymes, and tumor cell membranes and further facilitated interaction with cellular receptor and subsequent uptake..$^{5}$ These two causes made favorable for RV-c-SLN and more negative tumor cell/ vasculature charges - therefore tend to be responsible for the tumor-specific aggregation of RV-c-SLN. Literature reported the solid tumor had higher vascular permeability. Therefore, the nanoparticle $(<200 \mathrm{~nm})$ can significantly accumulate in tumor by passive targeting. ${ }^{8}$ Our experiment showed a particle size of RV-c-SLN around $140 \mathrm{~nm}$. Further, the size dependent passive targeting of RVc-SLN to the liver cells as well as tumor was confirmed by the biodistribution study in Albino wistar male rats bearing HCC. From Figure 7, the concentration of RV in the tumor was 2.6- and 1.4-times higher in the case of RVc-SLN over RV solution and RV-SLN at 8 hours after oral administration. Finally, it was concluded that RV-c-SLN caused significantly higher accumulation of RV in liver as well as tumor by oral administration of RV-c-SLN compared to RV solution and RV-SLN. In animal and human models, serum $\alpha$-fetoprotein (AFP) is measured as the most important marker in HCC development. ${ }^{8,14}$ DEN administered into rats developed HCC, and administration of optimized RV-c-SLN most significantly altered the level of $\alpha$-fetoprotein and caused strong anticancer effects. Furthermore, DEN-administered rats revealed a decrease in body weight as compared to other groups in association with HCC. Administration of RV-c-SLN in HCC bearing rats results to improve the body weight most significantly with improvement of disease condition. Another important measurement is liver weight in HCC, in the case of DENinduced $\mathrm{HCC}$, further the expansion of liver weight occurred by virtue of expansion of nodules and at last increased the liver weight. ${ }^{15}$ Apart from other groups of RV administered rat, RV-c-SLN found most effectively lowered the liver weight and reached to near the liver weight of the normal control group. Apart from these, the biochemical parameters are used for estimating that exhibits the particular cancer condition in the diagnosis, examining the expansion and calculating the response of the particular drug or therapy. Throughout cell proliferation, biochemical enzymes are more efficient and diversify with their expansion and metabolic turnover. ${ }^{12,14,15}$ Increased activation of enzymes is an indication of the relation between the various transformed cells under cancer conditions. During cancer, the cell organelles of hepatocytes have a transport function dysfunction, which allows these enzymes to leak through serum by regulation of plasma membrane permeability and thus induces modification of these enzymes in the cell and blood serum. ${ }^{16}$ The structural integrity and disruption to the cells contribute to the bloodstream and further release of enzymes. The elevated plasma production of AFP, ALT, and AST showed that hepatic dysfunction can be triggered by DEN. The abovementioned enzymes, including ALT and AST, are directly linked to amino acid transformation into 
ketoacids and participate in HCC development. ${ }^{17}$ The AFP, ALT, and AST level were most significantly reduced by RV-c-SLN, which indicates the chemo-protective effect on the hepatic and its functional performance. ${ }^{17}$ By metabolism, DEN produces free radicals, which are results to activation, development, and advancement in the various steps of carcinogenesis. Different scientist agreed that the DEN inducted HCC raises the output of reactive oxygen species (ROS) and disturbs the endogenous cell redox balance. ${ }^{12,17}$ Furthermore, the DEN group which causes lipid oxidative damage and accumulation of proteins resulted by imbalanced redox system. RV was found to be a powerful antioxidant and proved its action via antioxidant models in vitro and in vivo. ${ }^{17,18} \mathrm{RV}$-c-SLN therapy increases the endogenous antioxidant amount by substantially preventing oxidative stress through downregulating ROS generation/production, which avoids the decrease in membrane fluidity in contrast with DEN regulation. Further, RV-c-SLN therapy suggests that this cycle of oxidative stress is reversed and plays a vital role in preventing cancer growth. CAT and SOD are known to be the endogenous enzyme first line defense method. SOD acts against the radical superoxide $\left(\mathrm{O}_{2}\right)$ produced byproduct during oxidative phosphorylation. CAT and GPx play a crucial role in transforming $\mathrm{H}_{2} \mathrm{O}_{2}$ to $\mathrm{H}_{2} \mathrm{O} .^{12,18} \mathrm{GSH}$ plays a key role in removing free radicals through oxidative stress and preserving reduced cell status. ${ }^{12,18}$ The treatment of RV-c-SLN revealed the high level of GSH in contrast to the DEN control group, which altered the positive carcinogenesis environment. The content of MDA was increased in DEN induced rats and GPx, GSH, SOD, GST, and CAT were lowered in DEN-induced rats due to expansion of the tumor. The administration of RV-c-SLN most effectively reduces the level of MDA in DENinduced rats. RV-c-SLN caused the most significant boost up in the level of GPx, GSH, SOD, GST, and CAT. The balanced message and signaling flow acts to enhance coordination and communication of biochemical processes in the transport system of cell membrane-based enzymes. The influx and efflux of ions into the cell membranes at low $\mathrm{Na}^{+}$and high $\mathrm{K}^{+}$concentrations in the cytoplasm during ATP generation is the force for the transfer of these and other substances, including $\mathrm{Ca}^{2+}, \mathrm{H}^{+}$, and amino acids. ${ }^{19,20}$ The liver cell membranes have been of major importance in hepatobiliary and biliary transport. The regulation and fluidity of the liver plasma membrane and its structure will reassure the behavior of membrane attached enzymes and the cancer-arbitrated transport cycle. ${ }^{19,20}$ In HCC, lipid membrane peroxidation made abnormal structural and functional action of membranes and changed the membrane bound activity and its sensitivity. ${ }^{19,20}$ During tumor growth, particularly cancer was found to reduce membrane-bound enzyme activity. The DEN mediated HCC received a similar pattern, which further suggests the expansion of the rat tumor. Among RV treatment groups, RV-c-SLNs therapy most enhanced the membrane-bound enzyme activity either by decreasing lipid peroxidation or by normalizing disruption of the metabolism of $\mathrm{Ca}^{2+}$ and $\mathrm{K}^{+}$. The various cytokines, which include TNF- $\alpha$, IL- $1 \beta$, IL- 6 , and NF- $\kappa$ B, are produced by liver cells. ${ }^{21,22}$ TNF- $\alpha$ (NF- $\mathrm{kB}$ activator) is an inflammatory cytokine which concludes an important role in tumor development and cell proliferation. Another cytokine is IL-6, which is produced from the Kupffer cells via modifying the NF- $\mathrm{kB}$ signals of MyD88 to trigger the IL-1 $\alpha$ from the hepatocytes further. Clinical studies show that IL-6 serves as a hepatoprotective function under normal conditions, but the abnormal amount of IL- 6 continues to cause damage to the hepatic tissue during the disease. ${ }^{21,22}$ Later, it leads to cell cycle progression and apoptosis inhibition by modulation of Janus activated kinase signal transducers and transcription signaling pathway. The DEN group showed that IL-6 was increased, which was most significantly decreased by the RVc-SLNs to prove its anticancer effect. Another member of the interleukin family is IL-1 $\beta$, which plays a key role in the development and growth of inflammatory cascades. ${ }^{23}$ Many epidemiological studies indicate that low IL-1 $\beta$ concentration causes a local inflammatory reaction and raises the IL-1 $\beta$ concentration correlated with chronic inflammation and tissue damage. In patients with HCC, the increased amount of IL-1 $\beta$ has been identified and also the same in rats in the DEN group. ${ }^{23}$ RV-c-SLNs demonstrated the most important down-regulation of IL-1 $\beta$ and indicate an inflammatory reaction suppression. TNF- $\alpha$ and IL-6 are pro-inflammatory cytokines inducing the proliferation of tumor cells by expanding, initiating, and metastasis. Different clinical data suggest that TNF- $\alpha$ increases, directly enhances the NF- $\mathrm{KB}$ level, and causes inflammatory reactions. NF- $\mathrm{KB}$ is a part of five proteins that are found in different dimeric combinations and bound to DNA in NF- $\kappa B$ locations. ${ }^{24} \mathrm{NF}-\kappa \mathrm{B}$ is commonly found in tumor tissue and non-tumor tissue, but the $\mathrm{NF} \kappa \mathrm{B}$ concentration becomes substantially higher during disease, owing to inflammatory reactions in $\mathrm{HCC} .^{25}$ DEN induces upregulation of NF- $\kappa B, R V-c-S L N$ most commonly down- 
regulated the same, and was found to be an effective antioxidant or by an inhibitory inflammatory mechanism.

\section{Conclusions}

The present study concludes that optimized RV-c-SLN had a particle size of $139.27 \mathrm{~nm}$, entrapment efficiency of $83.8 \%$, and loading capacity of $24.3 \%$. The in vitro drug release determined an optimum release of drugs within the first 6 hours. The optimized RV-c-SLN cytotoxicity study in $\mathrm{HepG}_{2}$ cells revealed higher cytotoxicity over RV-SLN and Blank c-SLN. The RV-c-SLN, due to the cationic charge and particle size caused better antitumor action in terms of relative tumor volume and enhanced accumulation of RV in the liver tumor. The current data apply preclinically to the debate about the usefulness of RVc-SLN in HCC. RV-c-SLN gavage $(P<0.01)$ significantly reduced the development of free-radical and oxidative stress and regulated the activities of membrane bound enzymes through multiple mechanisms. Furthermore, the RV-c-SLN found remained stable over the 12-week storage at $25^{\circ} \mathrm{C} / 60 \% \mathrm{RH}$. Finally, we conclude that systemically optimized RV-c-SLNs have proved enhanced anticancer action as well as higher accumulation to HCC of RV over RV-SLN and RV solution in the treatment of $\mathrm{HCC}$.

\section{Disclosure}

The authors report no conflicts of interest in this work.

\section{References}

1. El-Serag HB. Hepatocellular carcinoma. $N$ Engl J Med. 2011;365 (12):1118-1127.

2. Kumar V, Bhatt PC, Rahman M, Al-Abbasi FA, Anwar F, Verma A. Umbelliferon- $\alpha$ - d -glucopyranosyl-(2 I $\rightarrow 1$ II)- $\alpha$-Dglucopyranoside ameliorates Diethylnitrosamine induced precancerous lesion development in liver via regulation of inflammation, hyperproliferation and antioxidant at pre-clinical stage. Biomed Pharmacother. 2017; 94:834-842. doi:10.1016/j.biopha.2017.07.047

3. Liu Z, Peng Q, Li Y, Gao Y. Resveratrol enhances cisplatin-induced apoptosis in human hepatoma cells via glutamine metabolism inhibition. BMB Rep. 2018;51(9):474-479. doi:10.5483/BMBRep.20 18.51.9.114

4. Rahman M, Beg S, Alharbi KS, et al. QbD-driven development of nano-antioxidant therapy containing solid lipid nanoparticles of ganoderic acid for the treatment of hepatocellular carcinoma. $J$ Pharm Innov. 2020. https://doi.org/10.1007/s12247-020-09450-4.

5. Doktorovová S, Santos DL, Costa I, et al. Cationic solid lipid nanoparticles interfere with the activity of antioxidant enzymes in hepatocelllar carcinoma cells. Int J Pharm. 2014;471(1-2):18-27. doi:10.10 16/j.ijpharm.2014.05.011

6. Tolba R, Kraus T, Liedtke C, Schwarz M, Weiskirchen R. Diethylnitrosamine (DEN)-induced carcinogenic liver injury in mice. Lab Anim. 2015;49(1_suppl):59-69. doi:10.1177/0023677215570086
7. Bhatt H, Rompicharla SVK, Komanduri N, et al. Development of curcumin-loaded solid lipid nanoparticles utilizing glyceryl monostearate as single lipid using QbD approach: characterization and evaluation of anticancer activity against human breast cancer cell line. Curr Drug Deliv. 2018;15(9):1271-1283. doi:10.2174/156720 1815666180503120113

8. Odoshima N, Udagawa C, Ando T, Fukuyasu H, Watanabe H, Nakabayashi S. Lipid nanoparticles for delivering antitumor drugs. Int J Pharm. 1997;146(1):81-92. doi:10.1016/S0378-5173(96)04779-5

9. Rodriguez Amado JR, Prada AL, Duarte JL, et al. Development, stability and in vitro delivery profile of new loratadine-loaded nanoparticles. Saudi Pharm J. 2017;25(8):1158-1168. doi:10.1016/j. jsps.2017.07.008

10. Yallapu MM, Gupta BK, Jaggi M, Chauhan SC. Fabrication of curcumin encapsulated PLGA nanoparticles for improved therapeutic effects in metastatic cancer cells. J Colloid Interface Sci. 2010;351 (1):19-29. doi:10.1016/j.jcis.2010.05.022

11. Pandya NT, Jani P, Vanza J, Tandel H. Solid lipid nanoparticles as an efficient drug delivery system of olmesartan medoxomil for the treatment of hypertension. Colloids Surf B Biointerfaces. 2018;16 5:37-44. doi:10.1016/j.colsurfb.2018.02.011

12. Rahman M, Al-Ghamdi SA, Alharbi KS, et al. Ganoderic acid loaded nano-lipidic carriers improvise treatment of hepatocellular carcinoma. Drug Deliv. 2019;26(1):782-793. doi:10.1080/10717544. 2019.1606865

13. Pereira I, Zielińska A, Ferreira NR, et al. Optimization of linalool-loaded solid lipid nanoparticles using experimental factorial design and long-term stability studies with a new centrifugal sedimentation method. Int $J$ Pharm. 2018;549(1-2):261-270. doi:10.10 16/j.ijpharm.2018.07.068

14. Ghosh D, Choudhury ST, Ghosh S, et al. Nanocapsulated curcumin: oral chemopreventive formulation against diethylnitrosamine induced hepatocellular carcinoma in rat. Chem Biol Interact. 2012;195 (3):206-214. doi:10.1016/j.cbi.2011.12.004

15. Sadik NAH, El-maraghy SA, Ismail MF. Diethylnitrosamine-induced hepatocarcinogenesis in rats: possible chemoprevention by blueberries. African J Biochem Res. 2008;2(3):81-87.

16. Thuy Thanh LT, Morita T, Yoshida K, et al. Promotion of liver and lung tumorigenesis in DEN-treated cytoglobin-deficient mice. $\mathrm{Am}$ J Pathol. 2011;179(2):1050-1060. doi:10.1016/j.ajpath.2011.05.006

17. Sakurai T, Maeda S, Chang L, Karin M. Loss of hepatic NF-kappa B activity enhances chemical hepatocarcinogenesis through sustained c-Jun N-terminal kinase 1 activation. Proc Natl Acad Sci USA. 2006;103(28):10544-10551. doi:10.1073/pnas.0603499103

18. Bishayee A, Barnes KF, Bhatia D, Darvesh AS, Carroll RT. Resveratrol suppresses oxidative stress and inflammatory response in diethylnitrosamine-initiated rat hepatocarcinogenesis. Cancer Prev Res (Phila). 2010;3(6):753-763. doi:10.1158/1940-6207.CAPR-09-0171

19. Langeswaran K, Jagadeesan AJ, Balasubramanian MP. Modulation of membrane bound ATPases and metabolizing enzymes against n-nitosodiethylamine (DEN) induced primary liver cancer in wistar albino rats. Int J Pharma Bio Sci. 2012;3(2):156-165.

20. Kamboj SS, Chopra K, Sandhir R. Hyperglycemia-induced alterations in synaptosomal membrane fluidity and activity of membrane bound enzymes: beneficial effect of $\mathrm{N}$-acetylcysteine supplementation. Neuroscience. 2009;162(2):349-358. doi:10.1016/ j.neuroscience.2009.05.002

21. Steensberg A, Keller C, Starkie RL, Osada T, Febbraio MA, Pedersen BK. IL-6 and TNF-alpha expression in, and release from, contracting human skeletal muscle. Am J Physiol Endocrinol Metab. 2002;283(6):E1272-E1278. doi:10.1152/ajpendo.00255.2002

22. Schindler R, Mancilla J, Endres S, Ghorbani R, Clark SC, Dinarello CA. Correlations and interactions in the production of interleukin-6 (IL-6), IL-1, and tumor necrosis factor (TNF) in human blood mononuclear cells: IL-6 suppresses IL-1 and TNF. Blood. 1990;75(1):40-47. 
23. Barashi N, Weiss ID, Wald O, et al. Inflammation-induced hepatocellular carcinoma is dependent on CCR5 in mice. Hepatology. 2013;58(3):1021-1030. doi:10.1002/hep.26403

24. Kumar V, Bhatt PC, Rahman M, et al. Fabrication, optimization, and characterization of umbelliferone $\beta$-D-galactopyranoside-loaded PLGA nanoparticles in treatment of hepatocellular carcinoma: in vitro and in vivo studies. Int $J$ Nanomedicine. 2017;12:67 47-6758. doi:10.2147/IJN.S136629
25. Yang J, Guo J, Yuan J. In vitro antioxidant properties of rutin. $L W T$ Food Sci Technol. 2008;41(6):1060-1066. doi:10.1016/j.lwt.2007. 06.010

\section{Publish your work in this journal}

The International Journal of Nanomedicine is an international, peerreviewed journal focusing on the application of nanotechnology in diagnostics, therapeutics, and drug delivery systems throughout the biomedical field. This journal is indexed on PubMed Central, MedLine, CAS, SciSearch ${ }^{\circledR}$, Current Contents ${ }^{\circledR} /$ Clinical Medicine, $^{2}$
Journal Citation Reports/Science Edition, EMBase, Scopus and the Elsevier Bibliographic databases. The manuscript management system is completely online and includes a very quick and fair peer-review system, which is all easy to use. Visit http://www.dovepress.com/ testimonials.php to read real quotes from published authors. 